\title{
Description of a new species of scorpion of the genus Lychas C.L. Koch, 1845 (Scorpiones: Buthidae) from Maharashtra, India
}

\author{
Zeeshan A. Mirza ${ }^{1}$ \& Rajesh V. Sanap ${ }^{2}$ \\ ${ }^{1}$ Zoology Department, Bhavans College, Andheri (W), Mumbai, Maharashtra 400058, India. \\ ${ }^{2}$ D5/2, Marol Police Camp, Marol Maroshi Road, Andheri (E), Mumbai, Maharashtra 400059, India. \\ Email: ${ }^{1}$ snakeszeeshan@gmail.com, ${ }^{2}$ rajeshvsanap@gmail.com
}

\begin{abstract}
A new species of buthid scorpion belonging to the genus Lychas C.L. Koch, 1845 is described from the degraded scrub of Aarey Milk Colony (Mumbai). Lychas aareyensis sp. nov. is similar to L. nigristernis, but can be differentiated based on a combination of morphological characters. Notes on natural history are also presented.
\end{abstract}

Keywords: Aarey Milk Colony, Lychas aareyensis sp. nov., Mumbai, northern Western Ghats, scorpion.

Date of publication (online): 26 April 2010 Date of publication (print): 26 April 2010 ISSN 0974-7907 (online) | 0974-7893 (print)

Editor: Vinod Khanna

\section{Manuscript details:}

Ms \# 02363

Received 10 December 2009

Final received 03 April 2010

Finally accepted 05 April 2010

Citation: Mirza, Z.A. \& R.V. Sanap (2010) Description of a new species of scorpion of the genus Lychas C.L. Koch, 1845 (Scorpiones: Buthidae) from Maharashtra, India. Journal of Threatened Taxa 2(4): 789-796.

Copyright: (C) Zeeshan A. Mirza \& Rajesh V. Sanap 2010. Creative Commons Attribution 3.0 Unported License. JoTT allows unrestricted use of this article in any medium for non-profit purposes, reproduction and distribution by providing adequate credit to the authors and the source of publication.

Author Details: ZeEshan A. Mirza is a student currently perusing a Bachelors degree in science from Bhavans College (Andheri, Mumbai) and is interested in herpetofaunal and scorpion documentation and their taxonomy. RAJESH V. SANAP has graduated with a Bachelors degree in arts and is interested in the study of reptiles and scorpions.

Author Contribution: ZAM and RVS equally contributed by conducting field, lab and writing work together.

Acknowledgment: See end of this article

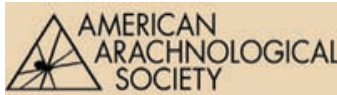

\section{INTRODUCTION}

The genus Lychas C.L. Koch, 1845 sensu lato, contains a number of small to medium sized ( 21 to $69 \mathrm{~mm}$ ) ground dwelling or arboreal scorpions characterized by the following set of characters: basic beta tricobothrial pattern (Sissom 1990); interocular area being horizontal; mesosomal tergites with one, two or three carinae; vesicle with a conspicuous, strong, triangular subaculear tooth (Kovařik 1997). The genus is represented by at least 37 species (Rein 2009), with maximum diversity in the tropical and sub-tropical regions of the world. Pocock (1900) in his work listed seven species from India, Tikader \& Bastawade (1983) described L. biharensis and L. kamshetensis adding two more species to the list and also speculated the occurrence of $L$. gravelyi in India without referring to any specimen or any published record and thus the record needs confirmation (Kovarik 1997). Later, Bastawade (1986) described L. kharpadi making it the eleventh species. Kovařik (1997) in his revision of the genus $L y c h a s$ described another two species $L$. rackae and L. hillyardi updating the list of thirteen species. Basu (1964) described L. decorata from Hazaribagh, Bihar province but did not provide any distinct character to separate the species from $L$. nigristernis. Furthermore he did not preserve the types (fide Kovařik, 1997), hence it was considered a synonym of L. nigristernis by Kovařik (1997) as Tikader \& Bastawade (1983) did not include this species in their work and no further specimens were reported by other authors as well (Kovařik 1997).

The Western Ghats region is a biodiversity hotspot known for rich endemic diversity (Myers et. al. 2000) that is not well documented (Giri \& Bauer 2008). Mumbai lies on the western fringe of the northern Western Ghats, and Sanjay Gandhi National Park in Mumbai, is home to more than 800 species of flowering plants, 33 of fish, more than 250 of birds, 40 of mammals (Anon. 1999), 62 of reptiles and 14 of amphibians (Mirza \& Pal 2008). The area is poorly known for invertebrate fauna, and an extensive survey to document scorpions has yielded one new species of the genus Lychas described here as Lychas aareyensis sp. nov.

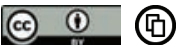

OPEN ACGESS | FREE DOWNLOAD
Abbreviations: d - dorsal; e - external; dt - dorsal terminal; db - dorsal basal; et external terminal; est - external sub-terminal; esb - external sub-basal; eb - external basal 


\section{MATERIAL AND METHODS}

Specimens in the field were located with the help of ultraviolet light detection by means of Arachnid ${ }^{\mathrm{TM}}$ A28, transferred to plastic jars and preserved in $70 \%$ ethyl alcohol. Photographs of live specimens were taken with a Canon EOS 1000D camera. Specimens were examined using a Labomed ${ }^{\mathrm{TM}}$ CSM2 stereo binocular microscope and measured with the help of Mitutoyo ${ }^{\mathrm{TM}}$ Dial caliper. The collection, after identification, has been deposited with the Bombay Natural History Society, Mumbai (BNHS). Descriptive terms and abbreviations follows Stahnke (1970) and Sissom et al. (1990).

\section{Systematics}

Order Scorpiones C.L. Koch, 1850

Superfamily Buthoidea C.L. Koch, 1837

Family Buthidae C.L. Koch, 1837

\section{Lychas aareyensis sp. nov.}

(Image 1-15, Figs. 1-3)

\section{Material examined}

Holotype: Female, 14.iii.2009, 198'43.73” \& \& 7252'55.39”E, 103m, Aarey Milk Colony, Mumbai, Maharashtra, India, coll. Rajesh Sanap and Zeeshan A. Mirza (BNHS SC-23).

Paratype: 2 females (BNHS SC-25/SC-26), 1 male (BNHS SC-24), same data as above.

\section{Etymology}

The specific epithet refers to Aarey, the type and only known locality for the new species.

\section{Diagnosis}

A small-sized scorpion which differs from other species of the genus as follows: median eye situated anteriorly in the ratio $1: 1.6 ; 13-13$ pectinal teeth; smaller size $31.65 \mathrm{~mm}$ (maximum); external granule absent on immovable and present on movable finger of female; trichobothrium $\mathrm{db}$ between et and est situated closer to est; pedipalp patella in shade of orange with faint brown reticulate markings or spots; metasomal segment I and II with 10 keels and III with eight.

\section{Description}

Measurements in Table 1. Coloration: Basically in a shade of orange or yellow, symmetrically marbled with brown producing an overall spotted appearance (Image 13). Carapace dark orange with random dark brown markings; eyes surrounded with black pigment. Mesosoma: brown with orange confluent spots on the distal regions of each tergites. Metasoma: segments I to III light brownish, segment IV more darker and segment $\mathrm{V}$ entirely black. Vesicle brownish-red. Venter yellowish with some diffuse brown spots on sternites V to VII. Chelicerae yellowish with dark variegated pigmentation; fingers dark brown with some light pigmentation. Pedipalp: yellowishorange with the femur and patella spotted or with reticulate markings; chela hand yellowish-orange; fingers darker and brownish. Legs yellowish with several diffuse spots

Surface of carapace coarsely granular with a few smooth patches (Image 1). A pair of median eyes situated anteriorly in the ratio 1:1.6. Median anterior and median central furrows shallow, the former wider; median posterior and post marginal furrows forming a deep triangular depression. Five pairs of lateral eyes present on anteriolateral portion with smooth lateral ocular tubercles of which two anterior pairs directed anterio-laterally. third pair posterio-laterally and last two pairs dorso-posteriorly and posteriorly respectively. Interocular portion black. Carinae absent, median lateral carinae poorly developed with a row of granules. Anterior margin introverted slightly and smooth; lateral margins finely crenulated and the posterior margin fairly smooth with some large granules on the periphery. Chelicerae smooth on basal segment (Image 5) with typical buthid dentition except only one tooth on ventral surface of immovable finger.

Femur carinae crenulated; the length of femur is shorter than carapace and patella. Patella carinated and dorso-inferior carinae evenly crenulated (Image 7). Manus smooth, without carinae (Image 6) and length of chelae twice the length of femur. Fingers as long as patella. smooth. Dentition on fingers overlapping. External granule absent on the immovable finger but a single external granule present on the movable finger and a strong apical tooth present in both sexes. Trichobothrial pattern on pedipalp as in Figs 1-3. Legs finely granular and carinated on femur and patella. Tibia smooth with

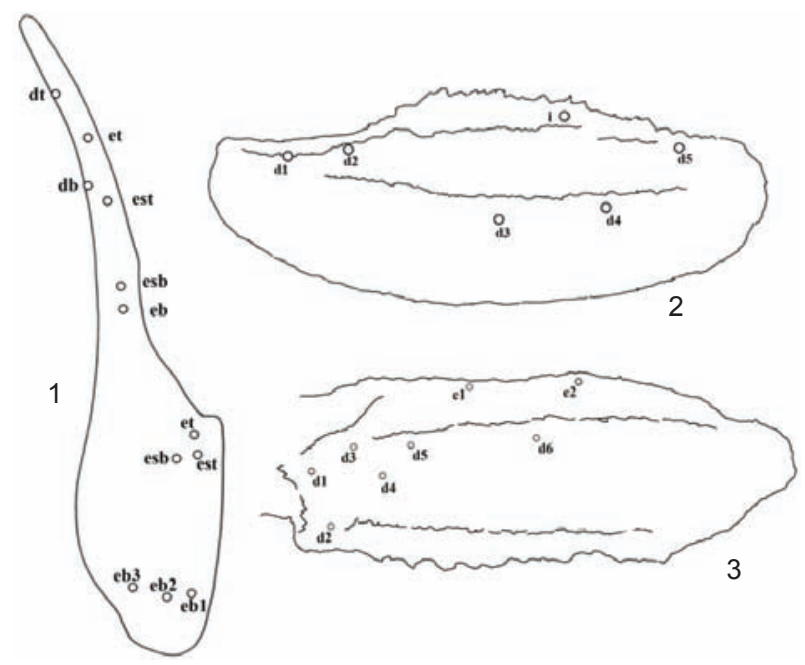

Figures 1-3. Lychas aareyensis sp. nov. female holotype tricobothrial pattern. Not on scale.

1 - Manus; 2 - Patella, dorsal; 3 - Femur, dorsal

$\mathrm{d}$ - dorsal; e - external; $\mathrm{dt}$ - dorsal terminal; $\mathrm{db}$ - dorsal basal; et external terminal; est - external sub-terminal; esb - external sub-basal; eb - external basal 

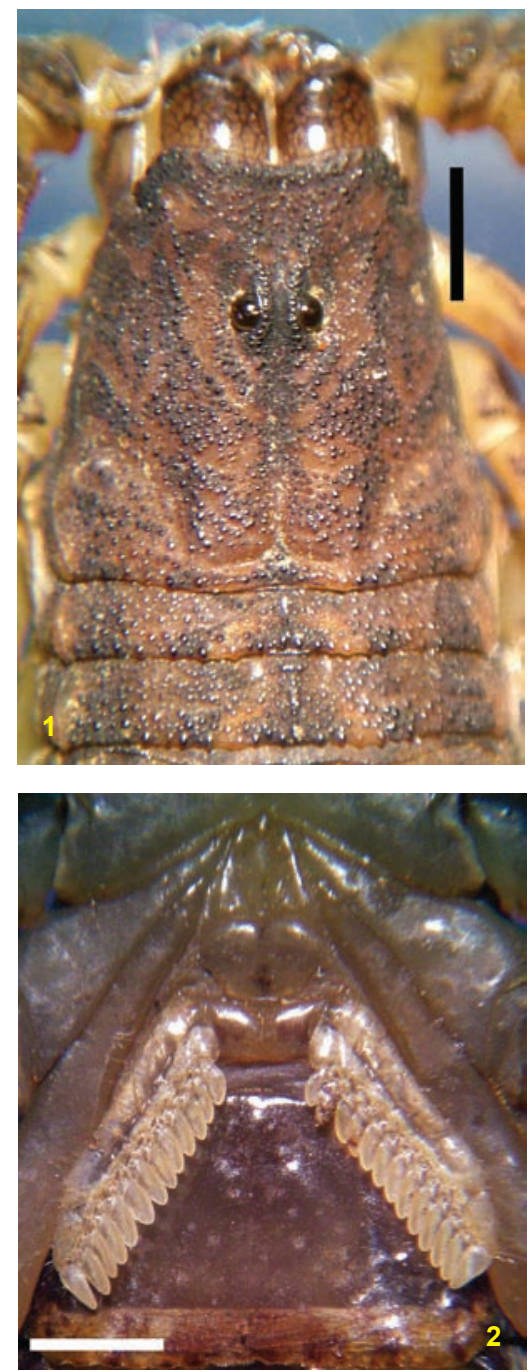
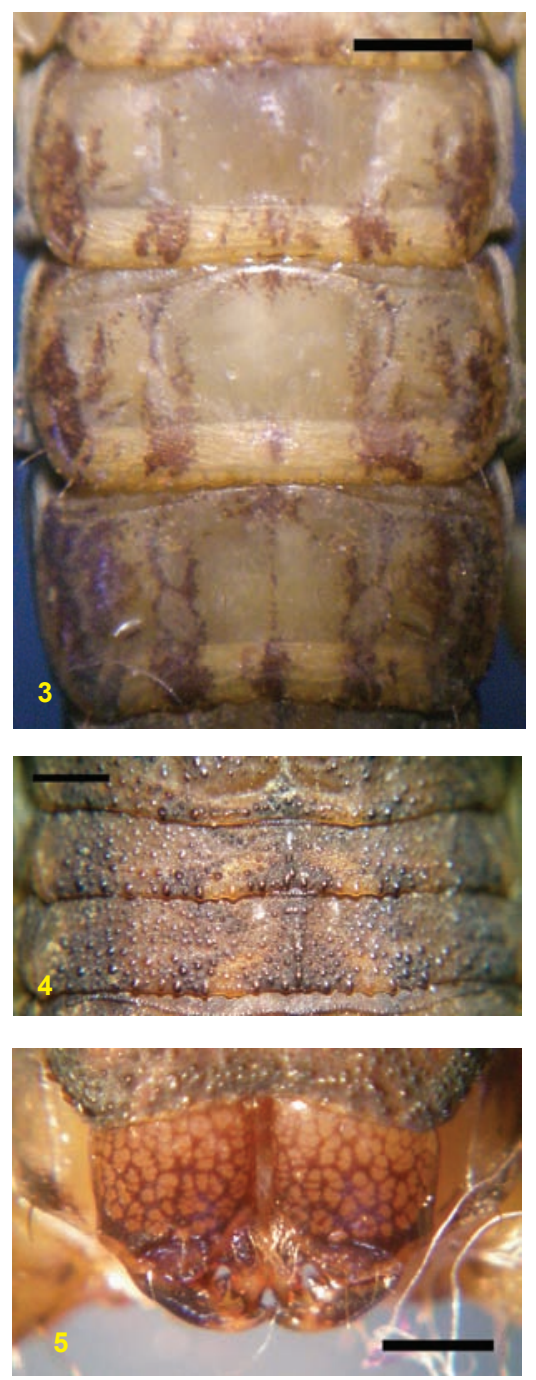

Images 1 to 9. Lychas aareyensis sp. nov, female holotype (BNHS SC23) (scale $1.0 \mathrm{~mm}$ )

1 - Carapace and Mesosoma; 2 - Genital operculum and pectinal teeth; 3 - Mesosomal tergites, dorsal; 4 - Mesosomal sternites, ventral; 5 - Chelicerae; 6 - Manus; 7 - Patella; 8 - Metasoma; 9 - Telson
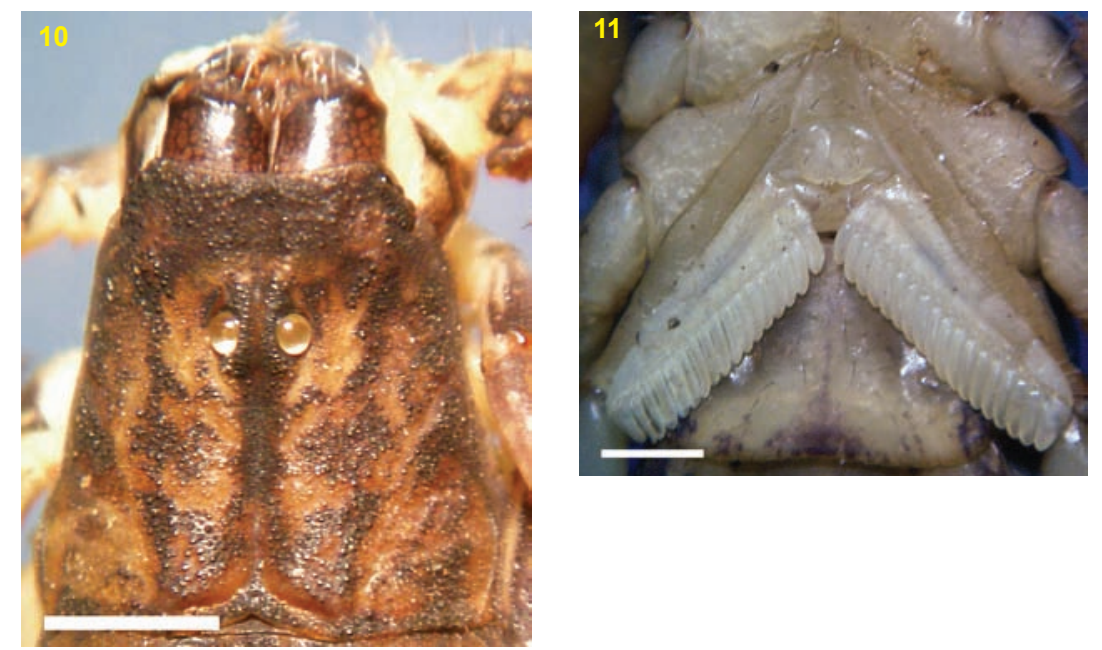

Images 10 to 12. Lychas aareyensis sp. nov. male paratype (BNHS SC24) (scale 1.0mm) 10 - Carapace; 11 - Genital operculum and pectined; 12 - Mesosoma ventral (no scale) 
Table 1. Detailed measurements of the types of Lychas aareyensis sp. nov. (in mm.).

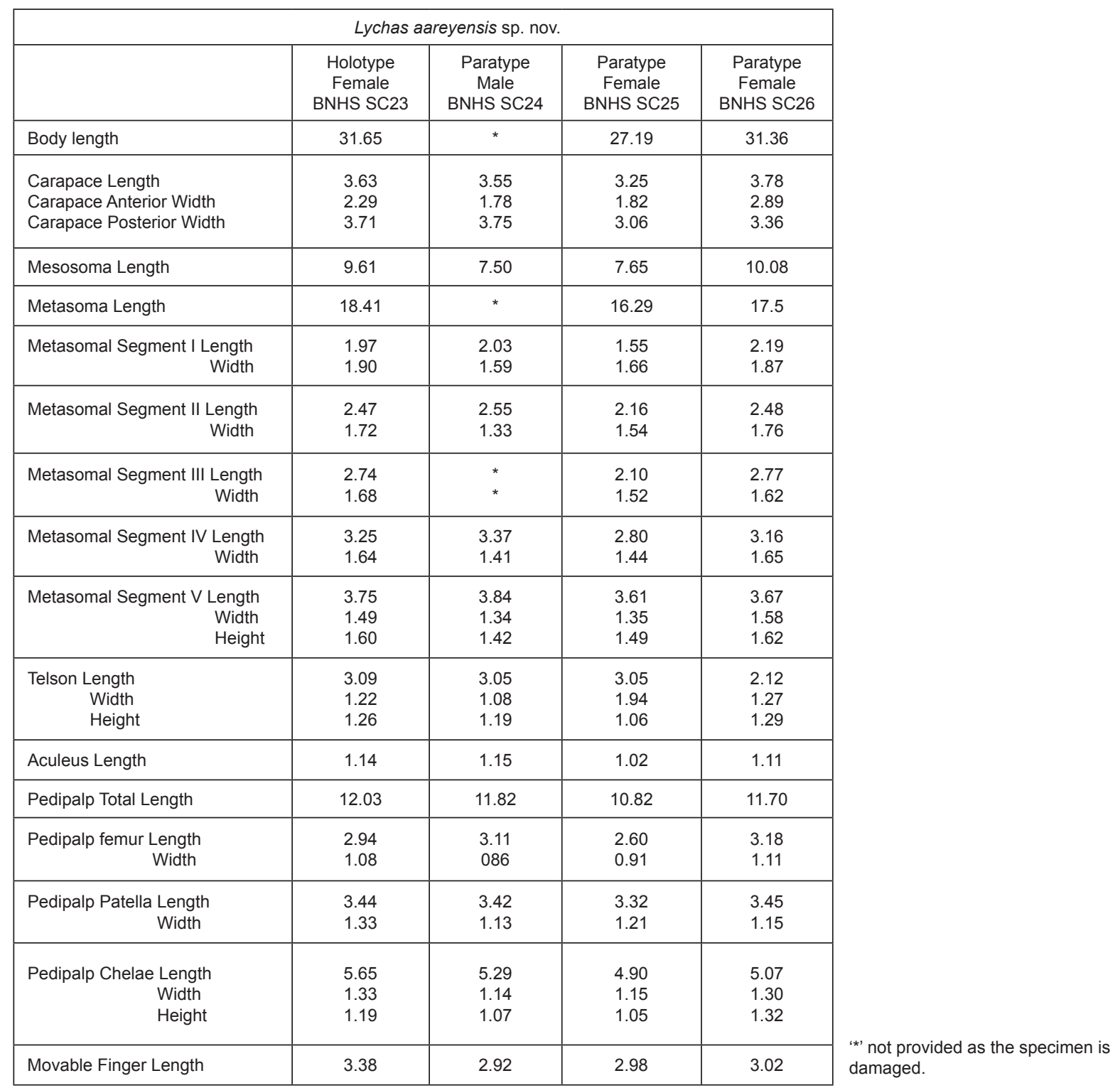

very short and inconspicuous tibial spur on III \& IV pairs. Tarsomere I almost as long as tibia but slender. Smooth and clothed with bristles on ventral portion. Tarsomere II delicate, thin and smooth covered thickly with paired bristles on ventral portion. A pair of claws present. Pectines well developed and more than four times as long as wide, middle lamellae divided into 8-9 small digits. Fulcra distinct. Lamellae and fulcra covered with setae. Pectinal teeth well developed; 13/14 in female (Image 2). Basal piece smooth not much sclerotized and invaginated on anterior margin forming a distinctive anterior notch as if composed of two halves fused medially. Genital operculum wider than long; paired genital papillae visible at the base of the genital operculum in the male. Cephalothoracic sternum triangular possessing a distinct median furrow and a small triangular basal pit.
Mesosoma: All tergites sparsely granular, more granular posteriorly (Images 1 \& 3 ). Tergites I-VI monocarinated. Lateral and posterior margins crenulated. Pretergal portion finely granular. Tergite VII more granular and with four crenulated carinae. Lateral and posterior margins granular. Sternites III-VI smooth; each sternite with a pair of book lungs (Image 4). Last sternite granular and carinated. Carinae weakly crenulated and granules obsolete. Lateral margins smooth. Posterior margin uneven. Presternal portion short and smooth.

Metasoma slightly more than five times as long as carapace (Image 8). Basal segment longer than wide. All segments carinated. Segments I and II with all ten carinae (paired ventral, ventrolateral, intermedian, dorsolateral, and dorsal carinae); all carinae crenulated. Segments III \& IV with eight carinae (intermedian carinae absent), 


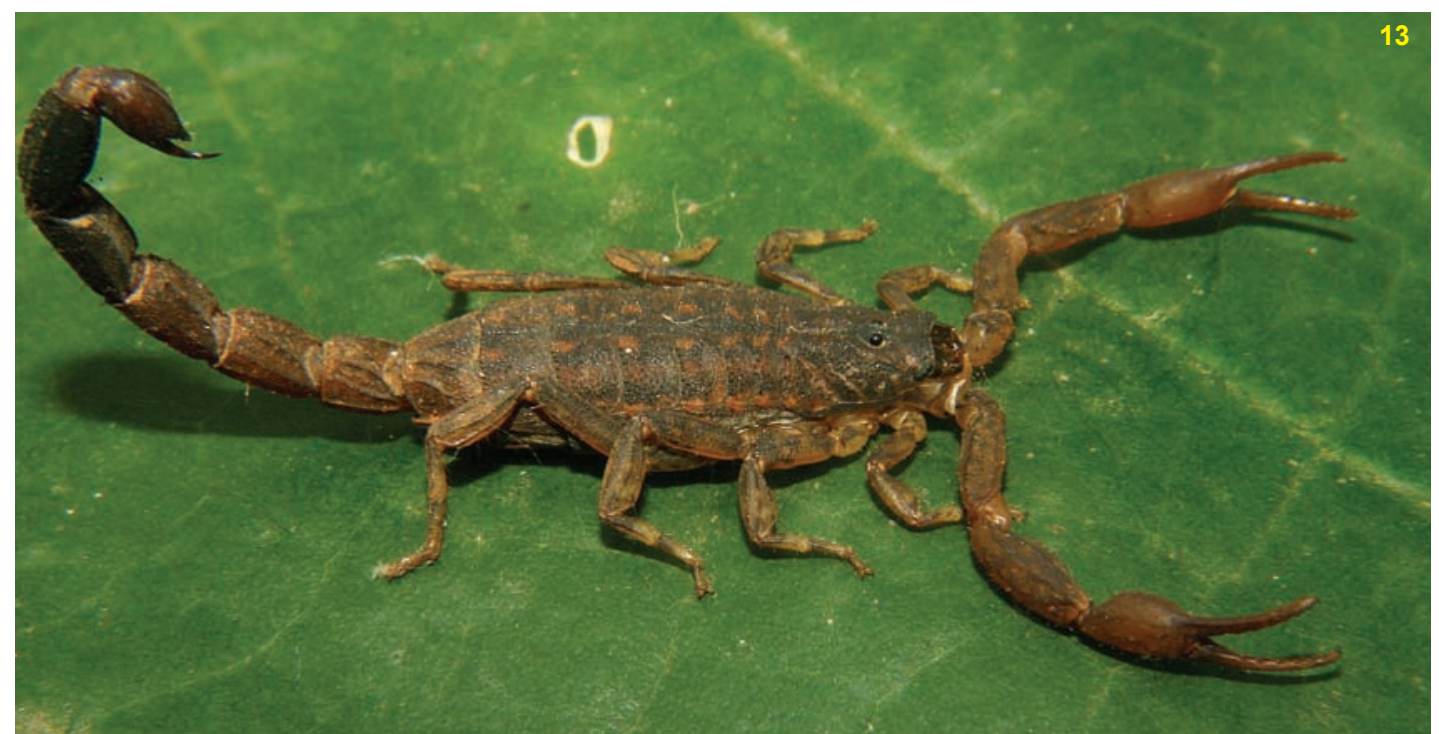

Image 13. Lychas aareyensis sp. nov. female holotype BNHS SC23 in life

all carinae crenulated and lateral carinae developed only on half of anterior portion of segment III; segment $\mathrm{V}$ with five (axial, paired ventrolateral and dorsolateral carinae). Dorsal carinae on segments I-IV weakly tuberculate posteriorly. Intercarinal portion weakly and much sparsely granular. Anterior and posterior margins of each segment smooth. Segment $\mathrm{V}$ almost as long as carapace; only inferior lateral and single inferior median carinae poorly granular and weakly crenulated. Intercarinal space poorly granular. Anal rim of this segment smooth. Telson (Image 9) slightly shorter than segment V. Vesicle as long as segment IV, weakly granular, ventral median crest ending posteriorly into a subaculear tubercle, provided with a pair of minute teeth on inner margin. Aculeus long, as long as the width of the vesicle; sharp, not much curved and dark on distal portion.

\section{Variations}

The paratypes match the description of the holotype but the male paratype (BNHS SC24) differs from the holotype as follows: carapace of male less granular than the female (Image 10); median eyes situated anteriorly in the ratio 1:1.7; a single external granule present on the immovable finger; pectines $17 / 18$ in number (Image $11)$; brightly coloured and with more confluent markings (Images 10 \& 12). The type series range from 27.19 to $31.65 \mathrm{~mm}$ in total length. The granules on the movable and immovable finger is variable presence and absence of external in the type series.

\section{Remarks}

A small sized scorpion (average 27 to $31 \mathrm{~mm}$ ) which closely resembles Lychas nigristernis, but can be easily distinguished (Lychas aareyensis sp. nov. vs. Lychas nigristernis) as follows- Median eye situated anteriorly in the ratio $1: 1.6$ or $1: 1.7$ vs. $1: 1.2$ in $L$. nigristermis; female with 13-13 pectinal teeth vs. $14-16$ in female $L$. nigristernis; smaller size $31.65 \mathrm{~mm}$ (maximum) vs. $45.2 \mathrm{~mm}$ in L. nigristernis; trichobothrium $\mathrm{db}$ between et and est situated closer to est vs. trichobothrium $\mathrm{db}$ between $\mathrm{dt}$ and et situated closer to et; pedipalp patella in shade of orange with faint brown reticulate markings or spots vs. pedipalp patella entirely black (Kovařik 1997; Tikader \& Bastawade 1983).

Lychas aareyensis sp. nov. may be distinguished from all other mainland Indian congeners on the basis of (nonoverlapping character): Median eye situated anteriorly in the ratio $1: 1.6$ or $1: 1.7$ (1:2 in $L$. nigristernis; $1: 2.5$ in $L$. gravelyi; 1: to 1:2.1 in L. mucronatus; 1:2.25 in L. rugosus; $1: 2.75$ in $L$. hendersoni), mesosomal tergites monocarinated ( tri-carinated in L. tricarinatus, L. laeviforns and $L$. scaber), $13-18$ pectines (21 in L. albimanus; 24 in L. biharensis; 20 in L. kamshetensis), third metasomal segment with eight keels (six in L. kharpadi), trichobothrium $\mathrm{db}$ between et and est situated closer to est (trichobothrium db between et and est situated closer to et in L. rackae; trichobothrium $\mathrm{db}$ between $\mathrm{dt}$ and et situated closer to et in L. hillyardi).

\section{Distribution and Natural History}

The type locality Aarey Milk Colony (1908'43.73"N \& $72^{0} 52^{\prime} 55.39$ 'E, $103 \mathrm{~m}$ ) is located to the south of Sanjay Gandhi National Park (Images 18). The habitat in which this species has been found is varied, from scrub to dense deciduous forest (Images $16 \& 17$ ) to open patches in the forest. As the forest in the Sanjay Gandhi National Park and adjoining protected areas share a similar biotype, it is quite possible that this species may yet be found in those areas as well as other parts of the northern Western Ghats. The scorpions were found mostly under boulders and on roads during the night. The holotype was found under a boulder from under a tree and all the 

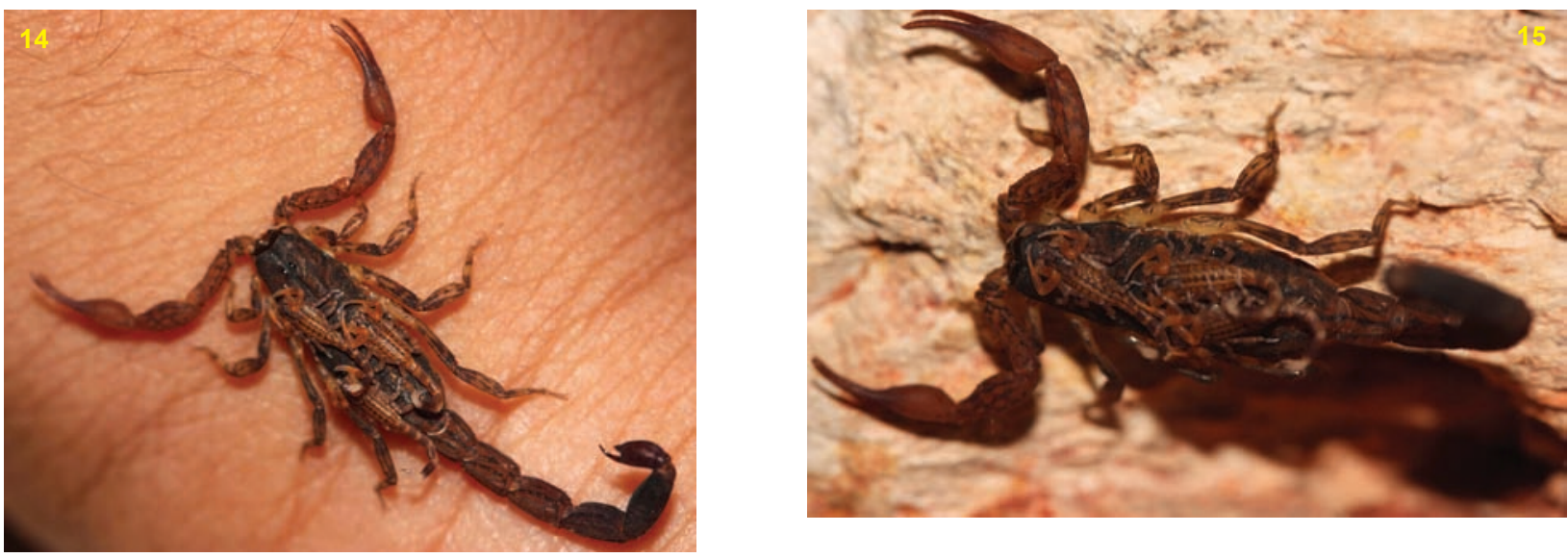

Images 14 \& 15. Lychas aareyensis sp. nov. female with juveniles (not collected)
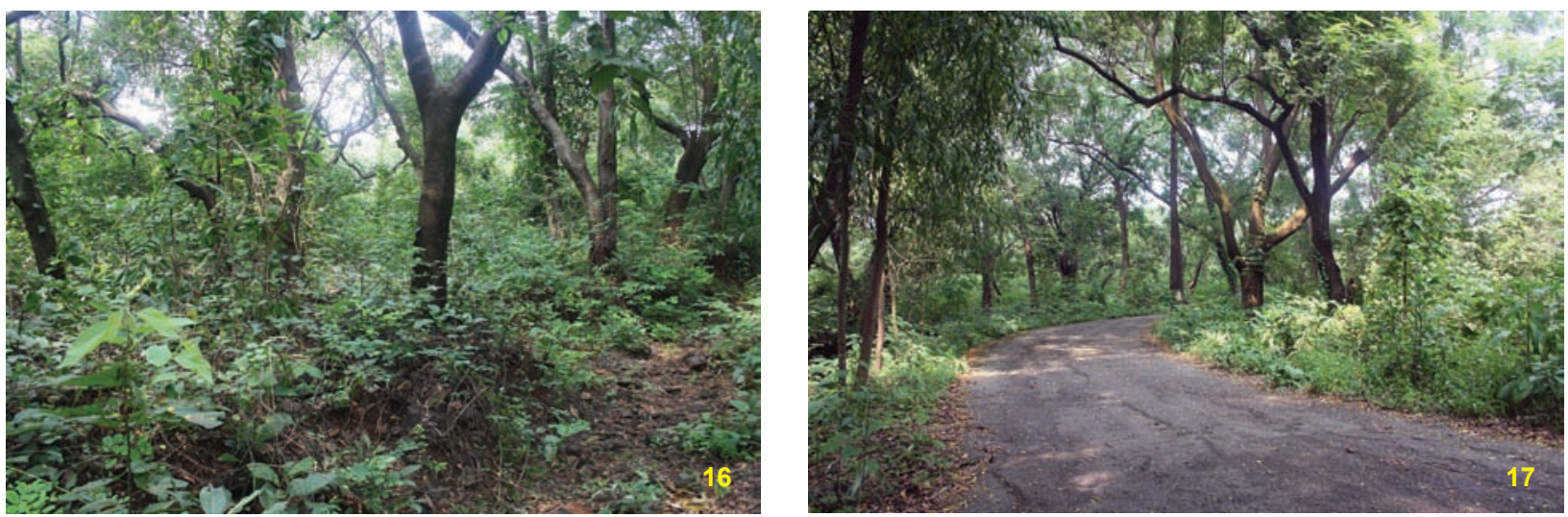

Images 16 \& 17. Habitat in which specimens of Lychas aareyensis sp. nov. were found.

paratypes were found on a road in a single night within ca. $500 \mathrm{~m}$. A female specimen collected on 31 March 2008 was retained in captivity for observations and on the 14 May 2008 it gave birth 13 juveniles (Image 14). The female started giving birth around $1100 \mathrm{hr}$ and continued till 1237hr. The female while giving birth had spread its pedipalp wide and open, Metasoma raised, front two pair of legs were held together to support the juvenile which would emerge from the genital operculum and climb on its back. The female would sway its pedipalp and metasoma as the juvenile emerged and would take a pause of 20 to 30 second after giving birth to a single juvenile. The juveniles stayed with the female until their third molt and later abandoned their mother. The juveniles just at birth were light colored and turned gradually darker as they grew older. While in captivity, the female was fed on a diet of cultured beetle larvae which were readily accepted. The scorpion would hold the larvae in its pedipalp far away from its body; sting it repeatedly until the prey ceased all signs of life and initiate the process of devouring it. We recorded other females (not collected) with six (Image 15) and another with eight juveniles in the field in the month of April. Members of this genus are also referred to as bark scorpions. Although numerous Lychas species have been found mostly under bark of trees, this species has only been found on the ground. The sympatric species observed at the type locality were Hottentotta tumulus, Hottentotta rugiscutis, Isometrus sp., Heterometrus phipsoni.

\section{DISCUSSION}

The description of Lychas aareyensis sp. nov. brings the total number of Lychas species in India to fourteen. A new species of scorpion from a city like Mumbai highlights our lack of knowledge on Indian scorpions. Tikader \& Bastawade (1983) listed and described 99 species of scorpions in Fauna of India, and with an intense survey this number will certainly increase. Additionally, a detailed revision of Indian scorpions is needed to popularize scorpion studies in India and assess their role in pest control. We lack natural history data on even the most common and widespread species of scorpions (Mirza et al. 2009). Kovařik (1997) mentions that the position of the trichobothrium $\mathrm{db}$ shows intraspecific variation in several species, whereas more than 20 specimens of $L$. aareyensis sp. nov. were observed with trichobothrium pattern same as in the types. Additionally, the presence and absence of external granules on the movable and 


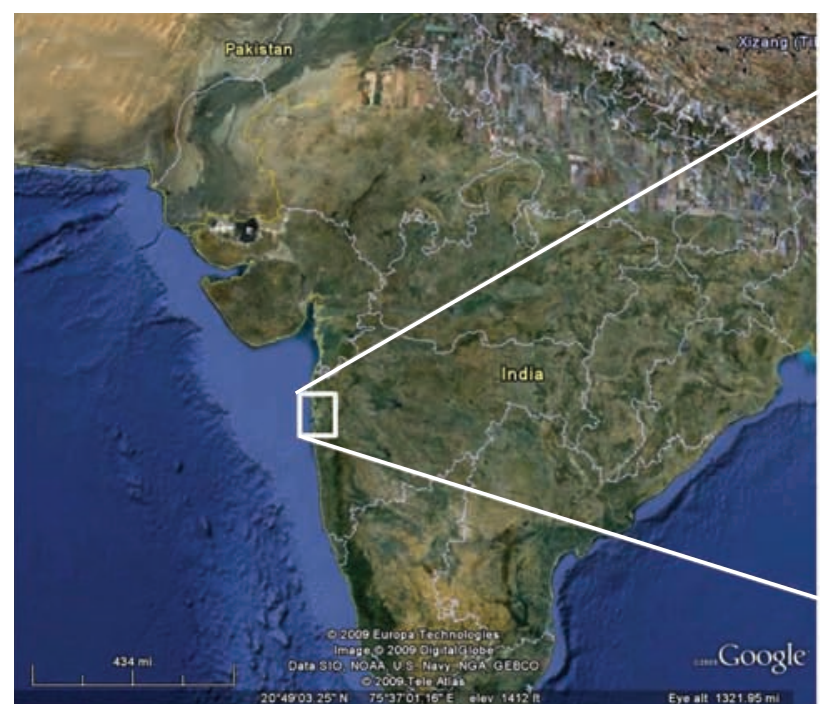

Image 18. Aarey Milk Colony, the type locality in Mumbai.

immovable fingers has been found to be variable in this species and hence needs further investigation on using it as a key taxonomic character at least in several species.

A major contribution towards documentation of Indian scorpions was made by R.I. Pocock (1900), and eightythreeyears later, Tikader \& Bastawade's (1983) compilation is the most recent work on Indian scorpions and still remains a noteworthy reference guide for researchers. Since Tikader \& Bastawade's (1983) compilation, several new species have been described and some genera have been revised shedding light on taxonomy of Indian scorpions (example Kovarík 1997, 2007). Thus there is a need to update the list of Indian scorpions following new taxonomic changes with incorporation of the recently described species. Additionally, several Indian species have been synonymized without formal justification and mostly based on the original description without having examined the type specimens. These synonyms need reassessment to verify their systematic status.

The type locality, Aarey Milk Colony (Image 18) is under severe threat from various anthropogenic activities and is in need of protection. A detailed survey conducted by us indicates that the area is rich with respect to its biodiversity but is poorly documented. Direct threat to this species includes clearing of forest for agricultural purpose and for bootlegging activities. Plantation of exotic trees has contributed towards destruction of habitat as they are incapable of holding soil and too weak to withhold the monsoon showers which lead to soil erosion. Additionally, forest fires cause maximum damage to this and other ground dwelling species.

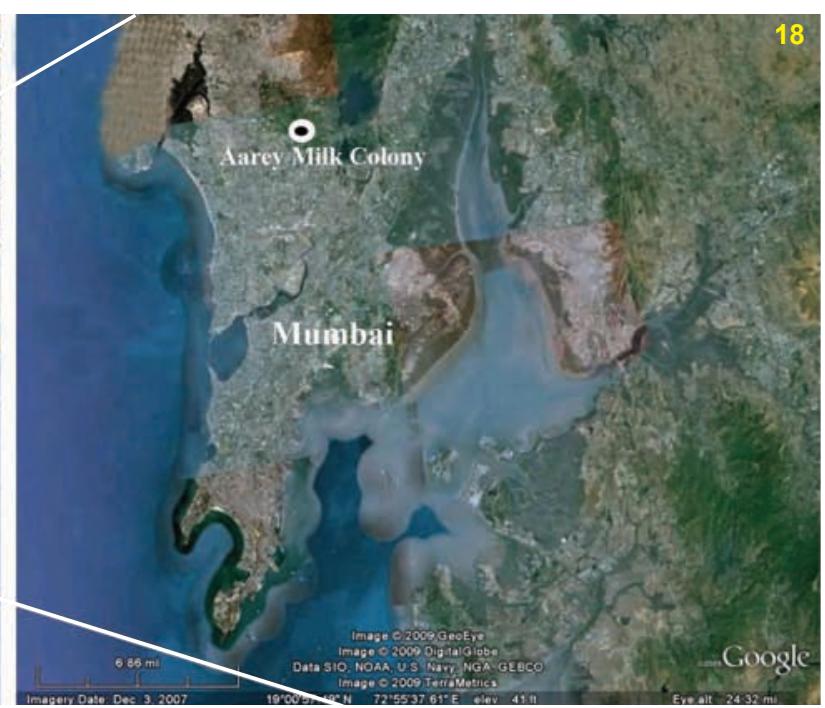

\section{REFERENCES}

Anon. (1999). Maharashtra Forest Department Management Plan 2000-2010, Sanjay Gandhi National Park.

Bastawade, D.B. (1986). New species of scorpion of the genus Lychas from Nasik District, Maharashtra, India. Journal of the Bombay Natural History Society 83: 634-637.

Basu, B.D. (1964). Observations on two species of Lychas. Journal of the Bengal Natural History Society 32: 99-103.

Giri, G. \& A. Bauer (2008). A new ground-dwelling Hemidactylus (Squamata: Gekkonidae) from Maharashtra, with a key to the Hemidactylus of India. Zootaxa 1700: 21-34.

Kovařik, F.(1997). Revision of the genera Lychasand Hemilychas, with description of six new species (Scorpiones: Buthidae). Acta Societas Zoologicae Bohemicae 61: 311-371.

Kovařik, F. (2007). Revision of the genus Hottentotta Birula, 1908, with Descriptions of Four New Species (Scorpiones, Buthidae). Euscorpius - Occasional Publications in Scorpiology 58: e1-107.

Mirza, Z \& S. Pal (2008). A checklist of reptiles and amphibians of Sanjay Gandhi National Park, Mumbai, Maharashtra Cobra II (4): 14-19.

Mirza, Z., K. Ullalkar \& G. Desouza (2009). Notes on the breeding of Hottentotta pachyurus Pocock, 1897 (Scorpiones: Buthidae). Journal of Threatened Taxa 1(3): 186-187.

Myers, N., R.A. Mittermeier, C.G. Mittermeier, G.A.B. da Fonseca \& J. Kent (2000). Biodiversity hotspots for conservation priorities Nature 403: 853-858.

Pocock, R.I. (1900). The Fauna of British India, including Ceylon and Burma. Arachnida. Taylor and Francis, London, 294pp.

Rein, J.O. (2009). The Scorpion Files. Norwegian University of Science and Technology, online at http://www.ntnu.no/ub/ scorpion-files/ accessed on $8^{\text {th }}$ October, 2009.

Sissom, W.D. (1990). Systematics, biogeography and paleontology, pp.64-160. In: Polis, G.A. (ed.). The Biology of Scorpions. Stanford University Press, Stanford, California.

Sissom, W.D., G.A. Polis \& D.D. Watt (1990). Laboratory and field methods, pp.445-461. In: Polis, G.A. (ed.). The Biology of Scorpions. Stanford University Press, Stanford, California.

Stahnke, H.L. (1970). Scorpion nomenclature and mensuration Entomological News 81: 297-316.

Tikader, B.K. \& D.B. Bastawade (1983). Scorpions (Scorpionida: Arachnida). In: The Fauna of India, Vol. 3. (Edited by the Director). Calcutta: Zoological Survey of India, 671pp. 
Acknowledgment: We are grateful to the American Arachnological Society for a generous grant to conduct field work. Special thanks to Agarwal Jan Seva Charitable Trust and Nisarg Trust for logistic support. Additionally we sincerely thank the following people- Jan $\mathrm{O}$. Rein, Dr. Parvish Pandya (Bhavans College) Dr. Anish Andheria, Shardul Bajikar, S.M. Maqsood Javed, Mihir Sule, V. Rathode, E. Das, Varsha Kulkarni, Ashish Jadhav, Gananan Korke, Sunny Patil, Sushil Bajgire and Saunak Pal. We would like to pay our deepest gratitude to Vishal Shah for his help and to all those who assisted with field work and review. Thanks are also due to the editor and reviewers for their inputs from which the manuscript benefited. We would sincerely like to thank Dr. D.B. Bastawade for his noteworthy contribution on Indian scorpions on which our knowledge is based. ZM wishes to thank Aamod Zambre for constant encouragement, help and support throughout the publication and preparation of this manuscript and also for his suggestions during the survey. We also thank Varad Giri and V. Patil for help with registration of specimens. 